\title{
Assessment of Color Vision Among School Children: A Comparative Study Between The Ishihara Test and The Farnsworth D-15 Test
}

\author{
Rajesh Kishor Shrestha, ${ }^{1}$ Gauri Shankar Shrestha ${ }^{2}$ \\ 'Department of Opthalmology, Nepal Medical College Teaching Hospital, Jorpati, Kathmandu, Nepal, ${ }^{2}$ Department of \\ Ophthalmology, Institute of Medicine, Maharaiguni, Kathmandu,Nepal.
}

\section{ABSTRACT}

Introduction: Color vision is one of the important attribute of visual perception. The study was conducted at different schools of Kathmandu to compare the findings of the Ishihara Pseudoisochromatic test and the Farnsworth D-15 test.

Method: A cross-sectional study was conducted among 2120 students of four schools of Kathmandu. Assessment included visual acuity measurement, slit lamp examination of anterior segment and fundus examination with direct ophthalmoscopy. Each student was assessed with the Ishihara pseudoisochromatic test and the Farnsworth D-15 test. The Chi-square test was performed to analyse color vision defect detected by the Ishihara test and the Farnsworth D-15 test.

Results: A total of 2120 students comprising of 1114 males (52.5\%) and 1006 females (47.5\%) were recruited in the study with mean age of 12.2 years (SD 2.3 years). The prevalence of color vision defect as indicated by the Ishihara was 2.6 and as indicated by the D-15 test was 2.15 in males.

Conclusion: For school color vision screening, the Ishihara color test and the Farnsworth D-15 test have equal capacity to detect congenital color vision defect and they complement each other.

Keywords: color vision; children; defect; Farnsworth D-15; Ishihara.

\section{INTRODUCTION}

Color vision is one of the important attribute of visual perception. Significant population suffer from an inherited conditions of red/green color defects besides other seen in different retinal and optic nerve disease. ${ }^{1}$

There are varieties of color vision tests such as the Ishihara Pseudoisochromatic plates, the Farnsworth Dichotomous D-15) test, the city university color vision test, De-saturated D-15 (L'Anthony's), Medmont C-100 or Oscar color vision test, Farnsworth Munsell 100-hue test and anomaloscope to identify color vision anomalies. They vary greatly in complexity, time to complete and the color vision problems they detect. ${ }^{2}$ The Ishihara Pseudoisochrmatic plate test is the most commonly used color vision test. They are relatively straightforward to administer, readily available and inexpensive. The colors that make up the figure and that constitute the background all fall on a common dichromatic confusion line. So, patients with anomalies of color vision have difficulty in seeing the figures embedded into the plates. ${ }^{3}$ The Ishihara test can't detect tritan plates and doesn't classify the severity. Mild deutans may pass the test and normal individual with poor discrimination may fail.4-6 The Farnsworth Dichotomous test consists of 15 colored caps that form a hue circle within the CIE diagram. It subtends

Correspondence: Dr. Rajesh Kishor Shrestha, Department of Opthalmology, Nepal Medical College Teaching Hospital, Jorpati, Kathmandu, Nepal. Email: drrajesh1@yahoo.com, Phone: +977. 9851012444 
Shrestha et al. Assessment of Color Vision Among School Children: A Comparative Study Between The Ishihara Test and The...

1.5 degree at $50 \mathrm{~cm}$ test distance. The 15 movable caps have Munsell value 5 and Chroma $4 .^{7}$ Though the Farnsworth D-15 test allow the differentiation of protan, deutan and tritan defects, it does not allow the differentiation of dichromats from anomalous trichromats, neither it detects minor defects and certain anomalous trichromats may pass the test. ${ }^{3,8,9}$

The Ishihara pseudoisochromatic plates are widely used in screening school children. In comparison the D-15 test aims to grade or dichotomies color deficiency people into two groups, pass or fail, and used only given to people identified as red green color deficient with a pseudoisochormatic screening test. ${ }^{10}$ The color vision defect would affect the course of their choice for the future career. Early detection of color vision defect is extremely important selecting the future career and counseling on the limitation of defect on the future career of the students, and minimizing psychological stress of having to select another profession after one has prepared for a specific one. The study was conducted at different schools of Kathmandu to compare the findings of the Ishihara pseudoisochromatic test and the Farnsworth D-15 test and to see if there was any agreement.

\begin{tabular}{|cccccc|}
\hline \multicolumn{5}{|l}{ Table 1. Pattern of color vision defect in males. } \\
\hline Test type & Protan No (\%) & Deutan No (\%) & Total defect No (\%) & Normal No (\%) & P \\
The D-15 test & $9(0.81)$ & $15(1.34)$ & $24(2.15)$ & $1090(97.85)$ & $\square^{2}=0.18, \mathrm{df}=1$, \\
$\begin{array}{c}\text { The Ishihara } \\
\text { test }\end{array}$ & $12(1.07)$ & $17(1.52)$ & $29(2.60)$ & $1085(97.4)$ & $\mathrm{p}=0.67$ \\
\hline
\end{tabular}

Table 2. An agreement between the Ishihara and the D-15 color vision tests.

Abnormal

${ }^{\mathrm{b}}$ The Farnsworth D-15 test

Normal

The Ishihara test

\begin{tabular}{|c|c|c|}
\hline abnormal & $\begin{array}{l}22 \text { (Positive } \\
\text { agreement) }\end{array}$ & 7 (false positive) \\
\hline Normal & 2 (false negative) & $\begin{array}{l}1083 \text { (negative } \\
\text { agreement) }\end{array}$ \\
\hline & $\begin{array}{l}\text { Sensitivity }{ }^{a} / \text { PPV }^{b} \\
(22 / 24=91.7 \%))\end{array}$ & $\begin{array}{l}\text { Specificity }{ }^{a} / N^{b} V^{b} \\
(1083 / 1090= \\
99.3 \%)\end{array}$ \\
\hline
\end{tabular}

$\mathrm{PPV}=$ positive predictive value, NPV $=$ negative predictive value
PPV $^{\mathrm{a}} /$ Sensitivity ${ }^{\mathrm{b}}(22 / 29=75.8 \%)$

NPVa/ specificity ${ }^{b}(1083 / 1085=99.8 \%)$

\section{METHODS}

In a descriptive cross-sectional study, 2120 students aged 8 to 15 years from four schools of Kathmandu were recruited in the study from 2012-2014. All the schools were sent written information detailing the purpose of the eye examination, and the permission was sought. A team comprising of an ophthalmologist, an optometrist and two ophthalmic assistant carried out eye examination.

Detailed eye examination was carried out including visual acuity assessment with internally illuminated Snellen chart at 6 meter, retinoscopy and subjective refraction, detailed anterior examination with the slit lamp (Haag Streit 900) and fundus examination with direct ophthalmoscopy. In case of suspected pathologic condition that may alter finding of color vision testing, dilated fundus examination was carried out after 30 minutes of instilling tropicamide eye drop $0.5 \%$ two drops at 5 minutes interval. The child was examined next day if dilated fundus examination revealed normal finding. Children who can't perform the color vision tests, whose response seemed unreliable and children who were not ready to participate in the study were excluded. Children with myopia greater than 6.00D, any suspected cases of retinal and optic nerve diseases and children with amblyopia or best spectacle corrected visual acuity less than 6/12 were also excluded from the study.

The Ishihara pseudoisochormatic color plates of 38 leaflets and the Farnsworth D-15 panel test were used in the study. Children were randomly selected to decide which test to perform first the Ishihara Pseudoisochromatic plates or the Farnsworth D-15 Panel test. Both of the tests were carried out under natural day light condition. The children were encouraged to read Ishihara test plate serially from $66 \mathrm{~cm}$ distance with the line of sight perpendicular to the pages. They were instructed to identify the numbers that could be seen on 
each page. The pages were presented monocularly for not more than 4 seconds for each plate. ${ }^{11}$ The number of plates with number misread was counted. If two or fewer errors were made, it was considered as normal where as six or more were color deficient. If no plates except the first plate was identified it was considered total color deficient. The guide book was referred to diagnose red-green deficiency, mild protan or deutan and strong protan or deutan.

Children are instructed to arrange the Farnsworth D-15 color caps from $50 \mathrm{~cm}$ distance in an order that the color next to the reference cap was the closest in color and so on for all other caps. This test was present to right eye first and then to the left eye. The reversing of the order of two caps was considered minor error. If two or fewer crossings were made was considered not to be severe. If more than two crossing were made, then the color vision defect could be said to be severe and orientation of the confusion loci which were described by the crossings on the plot, should describe whether the color vision defect was protan, deutan or tritan. A single mid test reversal was not considered as an error. ${ }^{12}$ If the confusion axis located approximately between the deutan and tritan axes, the color vision defect was said to be monochromatic. ${ }^{13}$

All data were entered into the statistical package for social studies (SPSS) version 17.0. The Chi-square test was performed to analyse color vision defect detected by the Ishihara test and the Farnsworth D-15 test. A p-value of $\leq 0.05$ was considered significant for $95 \%$ confidence interval.

\section{RESULTS}

A total of 2120 students comprising of 1114 males $(52.5 \%)$ and 1006 females $(47.5 \%)$ were recruited in the study with mean age of 12.2 years (SD 2.3 years). Pattern of color vision defect is presented in table 1. The prevalence of color vision defect as indicated by the Ishihara was 2.6 in males and as indicated by the D-15 test was 2.15 in males. None of the females had any color vision defect. Tritan color vision defect was also not noted as it was suggested by the D-15 test. The result of the test was statistically insignificant $(p=0.77)$. The deutan color vision defect was noted more commonly than the protan by both of the test types.

The agreement between the Ishihara test and the D-15 test was also analyzed (table 2). Though, color vision test with the Ishihara tests showed more deficient $(2.6 \%$ versus $2.15 \%)$, there is quite an agreement of it with the Farnsworth D-15 test. There was a high specificity against each other for color vision test (99.3$99.8 \%)$. However, the Ishihara test was more sensitive
$(91.7 \%)$ than the D-15 test $(75.8 \%)$ detecting color vision defect. In the same way, the positive predictive value of the D-15 test $(91.7 \%)$ was better than the Ishihara test $(75.8 \%)$.

\section{DISCUSSION}

The present study reports the prevalence of congenital color vision defect a well as compares the result of color vision defect between the Ishihara color vision test and the Farnsworth D-15 test.

The prevalence of color vision defect is noted to be $2.6 \%$ by the Ishihara and $2.15 \%$ by the D-15 tests among males. This finding is slightly less than the report of currently published literatures. ${ }^{14-19}$ The prevalence of color vision defect was reported to range from $3.83 \%$ to $8.18 \%$ among males and 0.13 to $0.44 \%$ in females. However, we didn't noted color vision defect in females. The $\mathrm{x}$-linked genetic inheritance pattern of the disorders explains the incidence being more in males and females being carriers. The $\mathrm{Y}$-linked inheritance sometimes manifests a confused pattern and reported in very few persons. This may possibly explains the possibility of color vision defect in females. ${ }^{20}$ However, our study lacks the genetic assessment.

In our study, the deutan color vision defect is seen higher than protan defect. This finding is in agreement with the zein et al (1990) report. In their study, deutan color $(3.2 \%)$ defect was significantly higher than the protan defect $(0.9 \%)$. However we noted deutan at 1.34 by the D-15 test and the protan at $0.81 \%$ in the D-15 test.

The Ishihara test consists of one demonstration plate, that everyone could see it, second series consist of transformation plates that a color deficieny person sees a different number than that is seen by normal; third series consist of vanishing plates that these plates are seen by normal individual but not by color deficient one, fourth series consist of hidden plates that the a number should be reported by color deficient person but not by someone with normal color vision and the last series consist of classification plates that are used when the screening section of the test identifies the presence of a colour vision defect. ${ }^{11}$ The classification plates in the Ishihara test are more effective for deuteranopes than protanopes, with a correct classification possible for around $90 \%$ of deuteranopes and around $80 \%$ of protanopes. Based on a fail criterion of three errors on the transformation and vanishing plates, the sensitivity of the Ishihara test is around $99 \%$ and the specificity is $94 \% .{ }^{11}$ The Farnsworth D-15 test is an arrangement color test that can detect and classify protan, deutan and tritan defect that otherwise can't be classified. In the study, there is a quite agreement between 
diagnosing color vision defect between the Ishihara and the D-15 tests, color vision test with the Ishihara tests showed more defect $(2.6 \%$ versus $2.15 \%)$ though. Both tests compliment each other by high specificity (99.3-99.8\%). The Ishihara test was more sensitive $(91.7 \%)$ than the D-15 test $(75.8 \%)$ in one way while the D-15 has more positive predictive value (91.7\%) than the Ishihara test (75.8\%). However, these findings are statistically insignificant $(\mathrm{p}=0.67)$.
The study do not take in account the genetic variability in a color deficient patient.

\section{CONCLUSION}

For school color vision screening, the Ishihara color test and the Farnsworth D-15 test have equal capacity to detect congenital color vision defect and they compliment each other.

\section{REFERENCES}

1. Steward SM, Cole BL. What do color vision defectives say about everyday tasks? Optom Vis Sci. 1989;66:288-95.

2. Committee on vision. Procedures for testing color vision report of working group 41, Washington DC: National Academy press 1981.

3. Schwartz SH. Anomalies of color vision. In: Visual perception: a clinical orientation. $3^{\text {rd }}$ edition, McGraw-Hill medical publishing Division; 2004:147-9.

4. Dain SJ. Clinical color vision tests. Clin Exp Optom. 2004;87:276-93.

5. DainSJ,GrayS, Tran L. Colorimetric analysis and performance assessment of the Hahn new pseudoisochromatic color vision test. Color Res Application. 1997; 23: 69-77.

6. Dian SJ. Evaluation of color vision testing made easy. Normal and defective color vision, Oxford England: Oxford University Press; 2003:347-53.

7. Paulson HM. Comparison of color vision tests used in the armed forces. In Judd DB, editor. Color vision. Washington, DC: National Academy of Science1973:34-64.

8. Farnsworth D. New Farnsworth Dichotomous test for color blindness, New York: Psychological corporation; 1947.

9. Linksz A. the Farnsworth Panel D 015 test. Am J ophthalmolol. 1966;62:27-37.

10. Birch J. Pass rate for the Farnsworth D-15 color vision test. Ophthal Physiol Opt. 2008; 28:259-64
11. Formankiewicz M. Assessment of color vision-color vision part 2. Continuing education and training. 2009:28-35. (Retrieved on $4^{\text {th }}$ August 2015 from http:/ / www.optometry. co.uk/uploads/articles/CET231009.pdf)

12. Bailey JE. Color vision. In: Eskridge BJ, Amos JF, Barlett JD. Clinical procedure in optometry. Philadelphia: JB Lippincott Company 1991:99-120.

13. Pokorny J, Smith VC, Verriest G, et al. Congenital and acquired color vision defects. New York. Grune and Stratton 1979:83-135.

14. Shrestha RK, Joshi MR, Shakya S, Ghising R. Color vision defects in school going children. JNMA J Nepal Med Assoc. 2010;50:264-6.

15. Mahajan OP, Gogna RS. Study of color blindness in school children. Indian J Physiol Pharmacol. 1977;21:59-62.

16. Zein ZA, Gene frequency and type of color blindness in Ethiopians. Ethiop Med J. 1990; 28:73-5.

17. Naresh S. Study of color blindness in Jat Sikhs. Indian J Physiol Pharmacol. 1995; 39:127-30.

18. Modarres M, Mirsamadi M, Peyman GA. Prevalence of congenital color deficiency in secondary school students in Tehran. Int Ophthalmol. 1996-97; 20: 221-2.

19. Kim HB, Lee SY, Choe JK, Lee JH, Ahu BH. The incidence of congenital color deficiency among Koreans. J Korean Med Sci. 1989;4:117-20.

20. Emery AEH. Elements of Medical Genetics. 6th ed. Churchill Livingstone Edinburg;1983 